VIRAL HEPATITIS

\title{
Liver fibrosis is not associated with steatosis but with necroinflammation in French patients with chronic hepatitis $C$
}

\author{
T Asselah, N Boyer, M-C Guimont, D Cazals-Hatem, F Tubach, K Nahon, H Daïkha, D Vidaud, \\ M Martinot, M Vidaud, C Degott, D Valla, P Marcellin
}

Background: In chronic hepatitis $C$, it has been suggested that steatosis could accelerate progression of fibrosis. However, results of the few published studies are controversial.

Aim: To determine the characteristics (epidemiological, biological, and histological) associated with steatosis and its relationship with liver lesions (grade of necroinflammation and stage of fibrosis) in patients with chronic hepatitis $C$.

See end of article for authors' affiliations Methods: From November 2000 to July 2001, untreated consecutive adults with chronic hepatitis C admitted for liver biopsy were included in this study. On the day of liver biopsy, a questionnaire for risk factors was completed prospectively, and a blood sample was obtained for laboratory analysis.

Correspondence to: Results: Our study included 290 patients (143 men, 147 women). Mean body mass index (BMI) was 24 DrT Asselah, Fédération d'Hépato-

Gastroentérologie and INSERM U481, Hôpital Beaujon, Clichy 92110 , France; tarikasselah@ hotmail.com (3.8) $\mathrm{kg} / \mathrm{m}^{2}$. Proportions of patients with genotypes 1 and 3 were, respectively, $48 \%$ and $18 \%$. A total of 135 patients $(46.6 \%)$ had steatosis. Liver steatosis, in multivariate analysis, was associated with hepatitis $C$ virus genotype 3, higher grade of necroinflammation, and higher BMI. There was no significant association between stage of fibrosis and liver steatosis. In multivariate analysis, high stage of fibrosis was associated with male sex, age over 50 years, high BMI, and high grade of necroinflammation.

Accepted for publication Conclusion: In our population of patients with chronic hepatitis C, steatosis does not seem to be an 28 May 2003 important determinant of liver fibrosis. High grade of necroinflammation is associated with a high stage of fibrosis.

T he hepatitis $\mathrm{C}$ virus (HCV) is a major cause of chronic liver disease worldwide, with approximately 170 million people infected. ${ }^{1}$ The severity of the disease varies widely from asymptomatic chronic infection to cirrhosis and hepatocellular carcinoma. Liver lesions are thought to be mainly related to immune mediated mechanisms. Factors influencing the outcome of chronic hepatitis $\mathrm{C}$, including age, sex, and alcohol consumption, are poorly understood. ${ }^{23}$ It is clear that these factors account only partially for the various outcomes of the disease.

Hepatic steatosis is a common histological feature of chronic hepatitis C. Various factors can be associated with hepatic steatosis, including obesity, high alcohol consumption, diabetes type II, and hyperlipidaemia. These factors may contribute to steatosis in patients with chronic hepatitis C. Three studies in chronic hepatitis $\mathrm{C}$ patients suggested an influence of steatosis on the progression of fibrosis. ${ }^{4-6}$ However, two other studies did not find an association between steatosis and liver fibrosis. ${ }^{78}$ Finally, only a few studies, with conflicting results, that included a relatively small number of patients and did not take into account all of the variables for steatosis and fibrosis have been reported.

Therefore, we decided to conduct a prospective study in a large group of patients with chronic hepatitis C, taking into account confounding factors for both steatosis and fibrosis (multivariate analysis) to investigate factors associated with steatosis and to determine the relationship between steatosis and liver lesions (grade of necroinflammation and stage of fibrosis).

\section{PATIENTS AND METHODS}

Patients

From November 2000 to July 2001, consecutive untreated patients with chronic hepatitis $\mathrm{C}$ who had undergone liver biopsy were included prospectively in this study. Chronic hepatitis $\mathrm{C}$ was defined by detectable anti-hepatitis $\mathrm{C}$ virus (HCV) and serum HCV RNA. Patients with markers of human immunodeficiency virus infection, detectable hepatitis B surface antigen, evidence of autoimmune processes, or those with an alcohol intake $>80 \mathrm{~g} /$ day were excluded. Among 335 patients, 45 were excluded: 40 with high alcohol intake, three with detectable hepatitis B surface antigen, and two with markers of human immunodeficiency virus infection. Therefore, we studied 290 patients.

\section{Data collection}

A questionnaire was completed prospectively on the day of the liver biopsy for every patient. The questionnaire included details on: sex, age (dichotomous: older or younger than 50 years), age at infection, source of infection, estimated duration of infection, alcohol consumption (g/day), tobacco consumption (tobacco equivalents per day), height, and weight. Duration of infection was calculated for 158 patients in whom an estimated date of infection based on the onset of drug use or blood transfusion was known. Body mass index (BMI) was calculated as weight $(\mathrm{kg})$ divided by (height $(\mathrm{m}))^{2}$ and definitions for overweight $(\mathrm{BMI}>25)$ and obesity (BMI >30) were used.

A fasting blood sample was obtained on the day of liver biopsy for analysis of the following parameters: serum alanine aminotransferase (ALT), $\gamma$-glutamyl transferase, bilirubin, alkaline phosphatase, serum glucose, cholesterol, and triglycerides.

Abbreviations: $\mathrm{HCV}$, hepatitis $C$ virus; $A L T$, alanine aminotransferase: $\mathrm{BMI}$, body mass index; $\mathrm{OR}$, odds ratio 
HCV genotyping was performed using reverse hybridisation with the line probe assay (LiPA; InGeN, Rungis, France). ${ }^{9}$

\section{Histological evaluation}

Liver histology was available for all 290 patients. Histological evaluation was performed without knowledge of the patients' clinical or blood data. All liver biopsies were read by one experienced pathologist and lesions were graded (necroinflammation) and staged (fibrosis score) according to the Metavir scoring system. ${ }^{10}$ Steatosis was graded as absent, mild $(<10 \%$ of hepatocytes), moderate $(10-30 \%$ of hepatocytes) or marked ( $>30 \%$ of hepatocytes), and massive ( $>60 \%$ of hepatocytes). Liver sections were stained with Perl's Prussian stain for iron grading. Stainable iron in the liver was graded as absent, moderate, or marked.

\section{Statistical analysis}

Firstly, we described the whole population using contingency tables. Secondly, we identified predictive factors for the presence of steatosis using both univariate (Pearson's $\chi^{2}$ test or Fisher's exact test, and the Student's $t$ test, as appropriate) and multivariate (logistic regression) analysis to assess the specific effect of each predictor. Factors included in the multivariate model were those with a significance level of $\mathrm{p}<0.20$ in the univariate analysis. Thirdly, using the same procedure, we identified predictive factors for the presence of high stage of fibrosis (Metavir score F2, F3, or F4). Age at infection and estimated duration of infection were not included in the multivariate analysis as this information was available for only 158 patients.

In these models, we have eliminated the hypothesis of multicolinearity between covariables in two different ways. Firstly, for all parameters of the logistic regression, we have compared each parameter with its standard error. As they were not greater than the parameters, one can be confident in the estimations of the parameters. Secondly, we have tested all of the interactions between covariables in each model and none was kept in the model after the stepwise procedure (data not shown).

Statistical analyses used the SAS Release 8.02 statistical software package.

\section{RESULTS}

The characteristics of the 290 patients are indicated in table 1 . The distribution of genotypes was as follows: 139 (48\%) genotype 1; 51 (18\%) genotype 3; and 59 (20\%) other genotypes. Mean BMI was $24 \mathrm{~kg} / \mathrm{m}^{2}$ with the following distribution: $171(59 \%)<25 \mathrm{~kg} / \mathrm{m}^{2} ; 78(27 \%) 25-30 \mathrm{~kg} / \mathrm{m}^{2}$; $20(7 \%)>30 \mathrm{~kg} / \mathrm{m}^{2}$; and unknown $21(7 \%)$. Histological results are shown in table 2 .

\section{Factors associated with the presence of steatosis}

In our sample, 135 patients $(46 \%)$ had steatosis. Steatosis was graded as mild in $21 \%$, moderate in $10 \%$, marked in $9 \%$, and massive in $6 \%$. In the univariate analysis (table 3 ), there was no significant association between the presence of steatosis and sex, age at infection, source of infection, alcohol consumption, tobacco consumption, cholesterol, triglyceride levels, or iron liver. Compared with patients without steatosis, patients with steatosis were older, had a higher BMI, a longer duration of disease, higher ALT levels, and higher glycaemia (table 3 ). Patients with steatosis were more frequently infected with HCV genotype 3. Liver lesions were more severe (both necroinflammation and fibrosis) in patients with steatosis.

In the multivariate analysis, high BMI (odds ratio (OR) 5.6 (95\% confidence interval (CI) 1.7-18.5)), high grade of necroinflammation (OR 3.1 (95\% CI 1.6-5.7)), and genotype 3 (OR 2.7 (95\% CI $1.4-5.5)$ ) were independently and
Table 1 Characteristics of 290 consecutive patients with chronic hepatitis C

\begin{tabular}{|c|c|}
\hline & $\begin{array}{l}\text { Chronic hepatitis C patients } \\
(\mathrm{n}=290)\end{array}$ \\
\hline Sex (male, n (\%)) & $143(49)$ \\
\hline Age $(y)^{*}$ & 46 (11.2) [19-73] \\
\hline \multicolumn{2}{|l|}{ Source of infection (n (\%)) } \\
\hline Blood transfusion & $70(24)$ \\
\hline Intravenous drug use & $91(31)$ \\
\hline Unknown & $129(45)$ \\
\hline Duration of infection $(y)^{*}$ & $21(7.4)[5-52]$ \\
\hline Body mass index $\left(\mathrm{kg} / \mathrm{m}^{2}\right)^{*}$ & $24(3.8)[16-38]$ \\
\hline \multicolumn{2}{|l|}{ Alcohol consumption (n (\%)) } \\
\hline Absent & $190(66)$ \\
\hline Present & $91(31)$ \\
\hline Unknown & $9(3)$ \\
\hline \multicolumn{2}{|l|}{ Tobacco consumption (n (\%)) } \\
\hline Absent & $154(53)$ \\
\hline Present & $117(40)$ \\
\hline Unknown & $19(7)$ \\
\hline ALT (IU/I) (median)* & $97(84.4)[12-691]$ \\
\hline Glycaemia $(\mathrm{mmol} / \mathrm{l})^{*}$ & 5.3 (1.7) [3.2-19.4] \\
\hline Cholesterol $(\mathrm{mmol} / \mathrm{l})^{*}$ & $4.8(1.0)[2-9]$ \\
\hline Triglycerides $(\mathrm{mmol} / \mathrm{l})^{*}$ & $1.3(0.8)[0.3-4.3]$ \\
\hline \multicolumn{2}{|l|}{ HCV genotype (n (\%)) } \\
\hline 1 & $139(48)$ \\
\hline 3 & $51(18)$ \\
\hline Other & $59(20)$ \\
\hline Unknown & $41(14)$ \\
\hline
\end{tabular}

Table 2 Liver histology in 290 consecutive patients with chronic hepatitis $\mathrm{C}$

\begin{tabular}{lc}
\hline & $\begin{array}{c}\text { Chronic hepatitis C patients } \\
\text { (n=290) }\end{array}$ \\
\hline Grade (n (\%)) & $3(1)$ \\
A0 & $209(72)$ \\
A1 & $69(24)$ \\
A2 & $9(3)$ \\
A3 & \\
Stage (n (\%)) & $4(1)$ \\
F0 & $177(61)$ \\
F1 & $73(25)$ \\
F2 & $21(8)$ \\
F3 & $15(5)$ \\
F4 & $155(53)$ \\
Steatosis (n (\%)) & $62(21)$ \\
Absent & $29(10)$ \\
Mild (0-10) & $27(9)$ \\
Moderate (10-30) & $17(6)$ \\
Marked (30-60) & \\
Massive (>60) & $244(84)$ \\
Liver iron (n (\%)) & $36(12)$ \\
Absent & $10(4)$ \\
Mild & \\
Marked & \\
\hline
\end{tabular}

significantly associated with the presence of steatosis (table 4). Fibrosis was not associated with steatosis.

\section{Factors associated with a high stage of fibrosis}

In our sample, 181 patients $(62 \%)$ had a low stage of fibrosis (F0-F1) and 109 patients (38\%) had a high stage of fibrosis $(\mathrm{F} 2-\mathrm{F} 4)$. In the univariate analysis (table 5 ) there was no significant association between the presence of high stage of fibrosis and source and duration of infection, alcohol consumption, tobacco consumption, glycaemia, cholesterol, triglycerides, and HCV genotype. Patients with a high stage of fibrosis were more frequently men, were older, had a higher 
Table 3 Factors associated with the presence of steatosis

\begin{tabular}{|c|c|c|c|}
\hline & $\begin{array}{l}\text { Absence of steatosis } \\
(n=155)\end{array}$ & $\begin{array}{l}\text { Presence of steatosis } \\
(n=135)\end{array}$ & $\mathrm{p}$ Value \\
\hline Sex (male, n (\%)) & $73(52)$ & $70(47)$ & 0.42 \\
\hline Age (n (\%)) & & & 0.04 \\
\hline$<50$ y & $109(70)$ & $73(54)$ & \\
\hline$\geqslant 50 y$ & $46(30)$ & $62(46)$ & \\
\hline Age at infection (n (\%)) & & & 0.21 \\
\hline$<30$ years & $65(84)$ & $62(77)$ & \\
\hline$\geqslant 30$ & $12(16)$ & $19(23)$ & \\
\hline Source of infection (n (\%)) & & & 0.23 \\
\hline Blood transfusion & $33(21)$ & $37(27)$ & \\
\hline Intravenous drug use & $46(30)$ & $45(33)$ & \\
\hline Unknown & 76 (49) & $53(39)$ & \\
\hline Duration of infection $(n=155)(y)^{*}$ & $19.4(6.9)$ & $22.4(7.6)$ & 0.01 \\
\hline Body mass index $\left(\mathrm{kg} / \mathrm{m}^{2}\right)(\mathrm{n}(\%))$ & & & 0.003 \\
\hline Normal $(\mathrm{BMI}<25)$ & $103(66)$ & $68(50)$ & \\
\hline Overweight $(25 \leqslant \mathrm{BMl}<30)$ & $36(23)$ & $42(31)$ & \\
\hline Obese $(B M I \geqslant 30)$ & $4(3)$ & $16(12)$ & \\
\hline Unknown & $12(8)$ & $9(7)$ & \\
\hline Alcohol consumption (n (\%)) & & & 0.29 \\
\hline Absent & $106(68)$ & $84(62)$ & \\
\hline Present & $43(28)$ & $48(36)$ & \\
\hline Unknown & $6(4)$ & $3(2)$ & \\
\hline Tobacco consumption (n (\%)) & & & 0.58 \\
\hline Absent & $79(51)$ & $75(56)$ & \\
\hline Present & $64(41)$ & 53 (39) & \\
\hline Unknown & 12 (8) & $7(5)$ & \\
\hline ALT (IU/I, median) & 78 (81) & $119(83)$ & 0.0001 \\
\hline Glycaemia $(\mathrm{mmol} / \mathrm{l})^{*}$ & $5.0(1.3)$ & $5.7(2.1)$ & 0.002 \\
\hline Cholesterol $(\mathrm{mmol} / \mathrm{l})^{*}$ & $4.9(1.1)$ & $4.7(1.0)$ & 0.18 \\
\hline Triglycerides $(\mathrm{mmol} / \mathrm{l})\left(\mathrm{mmol} / \mathrm{l}^{*}\right.$ & $1.1(0.7)$ & $1.2(0.8)$ & 0.17 \\
\hline HCV genotype (n (\%)) & & & 0.03 \\
\hline 3 & $19(12)$ & $32(24)$ & \\
\hline Other & $114(74)$ & $84(62)$ & \\
\hline Unknown & $22(14)$ & 19 (14) & \\
\hline Grade (histology) (n (\%)) & & & $<0.0001$ \\
\hline A0-Al & $129(83)$ & $83(61)$ & \\
\hline A2-A3 & $26(17)$ & $52(39)$ & \\
\hline Stage (histology) (n (\%)) & & & $<0.0001$ \\
\hline FO-F1 & $111(72)$ & $70(52)$ & \\
\hline F2-F3-F4 & $44(28)$ & 65 (48) & \\
\hline
\end{tabular}

Table 4 Factors associated with the presence of steatosis (multivariate analysis; $n=236$ )

\begin{tabular}{lllll}
\hline & & Odds ratio & $95 \% \mathrm{Cl}$ & $\mathbf{p}$ Value \\
\hline \multirow{3}{*}{ BMI } & Normal & 1 & & 0.008 \\
& Overweight & 1.8 & $1.0-3.2$ & \\
Genotype & Obesity & 5.6 & $1.7-18.5$ & 0.004 \\
\multirow{2}{*}{ Grade } & Other & 1 & $1.4-5.5$ & 0.0004 \\
& Genotype & 2.7 & $1.6-5.7$ & \\
\hline
\end{tabular}

This multivariate analysis used logistic regression with stepwise procedure. Variables included in the model were age (dichotomous: younger or older than 50 years), body mass index (BMI), genotype 3, alanine

aminotransferase, glycaemia, cholesterol, triglycerides, stage, and grade.

$95 \% \mathrm{Cl}, 95 \%$ confidence interval.

BMI, higher ALT levels, a higher grade of necroinflammation, and had steatosis more frequently.

In the multivariate analysis (table 6), high stage of fibrosis was associated with male sex (OR 2.4 (95\% CI 1.2-4.4)), high BMI (OR 1.9 (95\% CI 1.0-3.7)), and high grade of necroinflammation (OR 10.1 (95\% CI 5.2-19.7)). Steatosis was not associated with high stage of fibrosis.

\section{DISCUSSION}

In our population of 290 consecutive patients with chronic hepatitis C, using multivariate analysis, steatosis was independently and significantly associated with a high BMI, high grade of necroinflammation, and genotype 3, but was not associated with the stage of fibrosis. In addition, using multivariate analysis, we found that moderate or severe fibrosis was associated with male sex, high BMI, and high grade of necroinflammation.

In univariate analysis, there was an association between steatosis and high stage of fibrosis. However, using multivariate analysis, there was no association between steatosis and high stage of fibrosis. Recent studies on HCV showed an association between steatosis and high stage of fibrosis and suggested that steatosis accelerates progression of liver fibrosis. ${ }^{4-6}$ In these studies, risk factors for non-viral steatosis were more common than in our population. Therefore, we believe that in patients with chronic hepatitis $\mathrm{C}$, the 
Table 5 Factors associated with moderate or severe fibrosis (univariate analysis)

\begin{tabular}{|c|c|c|c|}
\hline & $\begin{array}{l}\text { Fibrosis F0-F1 } \\
(\mathrm{n}=181)\end{array}$ & $\begin{array}{l}\text { Fibrosis F2-F4 } \\
(n=109)\end{array}$ & $p$ Value \\
\hline Sex (male, $\mathrm{n}(\%))$ & $80(44)$ & $63(58)$ & 0.02 \\
\hline Age (n (\%)) & & & $<0.0001$ \\
\hline$<50 y$ & $133(73)$ & $49(45)$ & \\
\hline$\geqslant 50 y$ & $48(27)$ & $60(55)$ & \\
\hline Age at infection (n (\%)) & & & 0.05 \\
\hline$<30 y$ & $89(49)$ & $38(35)$ & \\
\hline$\geqslant 30 y$ & $16(9)$ & $15(14)$ & \\
\hline Unknown & $76(42)$ & $56(51)$ & \\
\hline Source of infection (n (\%)) & & & 0.2 \\
\hline Blood transfusion & $44(24)$ & $26(24)$ & \\
\hline Intravenous drug use & $63(35)$ & $28(26)$ & \\
\hline Unknown & $74(41)$ & $55(50)$ & \\
\hline Duration of infection $(y)^{*}$ & $20.3(7.6)$ & $22.2(7.6)$ & 0.15 \\
\hline Body mass index $\left(\mathrm{kg} / \mathrm{m}^{2}\right)$ (n (\%)) & & & 0.002 \\
\hline Normal $(\mathrm{BMI}<25)$ & $122(67)$ & $49(45)$ & \\
\hline Overweight $(25 \leqslant$ BMl $<30)$ & $39(22)$ & $39(36)$ & \\
\hline Obese $(B M I \geqslant 30)$ & $9(5)$ & $11(10)$ & \\
\hline Unknown & $11(6)$ & $10(9)$ & \\
\hline Alcohol consumption (n (\%)) & & & 0.79 \\
\hline Absent & $121(67)$ & $69(63)$ & \\
\hline Present & $55(30)$ & $36(33)$ & \\
\hline Unknown & $5(3)$ & $4(4)$ & \\
\hline Tobacco consumption (n (\%)) & & & 0.19 \\
\hline Absent & $91(50)$ & $63(58)$ & \\
\hline Present & $80(44)$ & $37(34)$ & \\
\hline Unknown & $10(6)$ & $9(8)$ & \\
\hline ALT (IU/I, median) & $65(81)$ & $105(83)$ & $<0.0001$ \\
\hline Glycaemia (mmol/l) & $5.2(1.7)$ & $5.5(1.8)$ & 0.14 \\
\hline Cholesterol (mmol/l) & $4.9(1.2)$ & $4.7(0.9)$ & 0.12 \\
\hline Triglyceride (mmol/l) & $1.1(0.7)$ & $1.3(0.7)$ & 0.17 \\
\hline HCV genotype (n (\%)) & & & 0.41 \\
\hline 3 & $33(18)$ & $18(17)$ & \\
\hline Other & $119(66)$ & 79 (72) & \\
\hline Unknown & $29(16)$ & $12(11)$ & \\
\hline Grade (histology) (n (\%)) & & & $<0.0001$ \\
\hline $\mathrm{A} 0-\mathrm{Al}$ & $162(90)$ & $50(46)$ & \\
\hline A2-A3 & $19(10)$ & $59(54)$ & \\
\hline Steatosis (histology) (n (\%)) & & & 0.0005 \\
\hline Absent & $111(61)$ & $44(40)$ & \\
\hline Present & $70(39)$ & $65(60)$ & \\
\hline
\end{tabular}

Table 6 Factors associated with moderate or severe fibrosis (multivariate analysis; $\mathrm{n}=269$ )

\begin{tabular}{|c|c|c|c|c|}
\hline & & Odds ratio & $95 \% \mathrm{Cl}$ & p Value \\
\hline Age & $\begin{array}{l}<50 y \\
\geqslant 50 y\end{array}$ & $\begin{array}{l}1 \\
2.6\end{array}$ & $1.4-5.0$ & 0.002 \\
\hline Sex & $\begin{array}{l}\text { Female } \\
\text { Male }\end{array}$ & $\begin{array}{l}1 \\
2.4\end{array}$ & $1.2-4.4$ & 0.008 \\
\hline BMI & $\begin{array}{l}\text { Normal } \\
\text { Overweight } \\
\text { Obesity }\end{array}$ & $\begin{array}{l}1 \\
1.9 \\
2.5\end{array}$ & $\begin{array}{l}1.0-3.7 \\
0.8-7.8\end{array}$ & 0.08 \\
\hline Grade & $\begin{array}{l}\mathrm{A} 0-\mathrm{A} 1 \\
\mathrm{~A} 2-\mathrm{A} 3\end{array}$ & $\begin{array}{l}1 \\
10.1\end{array}$ & $5.2-19.7$ & $<0.0001$ \\
\hline
\end{tabular}

This multivariate analysis used logistic regression with stepwise procedure. Variables included in the model were age (dichotomous: younger or older than 50 years), sex, body mass index (BMI), tobacco consumption, alanine aminotransferase, glycaemia, cholesterol, triglycerides, grade, and stage.

$95 \% \mathrm{Cl}, 95 \%$ confidence interval.

conflicting results regarding the association between steatosis and high stage of fibrosis may be related to the characteristics of the populations. In a recent study from the USA $^{6}{ }^{6}$ where both steatosis $(p=0.04)$ and high grade of necroinflammation $(\mathrm{p}<0.0001)$ were associated with high stage of fibrosis, the population was completely different from our study in terms of metabolic disorders. In the same study, mean BMI was $28.5 \mathrm{~kg} / \mathrm{m}^{2}$ with the following distribution: $31 \%<25 \mathrm{~kg} / \mathrm{m}^{2}, 37 \% \quad 25-30 \mathrm{~kg} / \mathrm{m}^{2}$, and $32 \%$ $>30 \mathrm{~kg} / \mathrm{m}^{2}$. This means that $69 \%$ of patients were overweight and $32 \%$ were obese. In our population, mean BMI was $24 \mathrm{~kg} / \mathrm{m}^{2}$ with the following distribution: $59 \%<25 \mathrm{~kg} / \mathrm{m}^{2}$, $27 \% 25-30 \mathrm{~kg} / \mathrm{m}^{2}, 7 \%>30 \mathrm{~kg} / \mathrm{m}^{2}$, and $7 \%$ unknown.

A link between steatosis and high BMI has already been reported in previous studies. ${ }^{46}$ The prevalence of metabolic disorders (hyperlipidaemia and diabetes) was low in our population and therefore its impact on steatosis could not be evaluated. These metabolic disorders (hyperlipidaemia and diabetes) and obesity are known risk factors for nonalcoholic steatohepatitis. Indeed, liver fibrosis can develop 


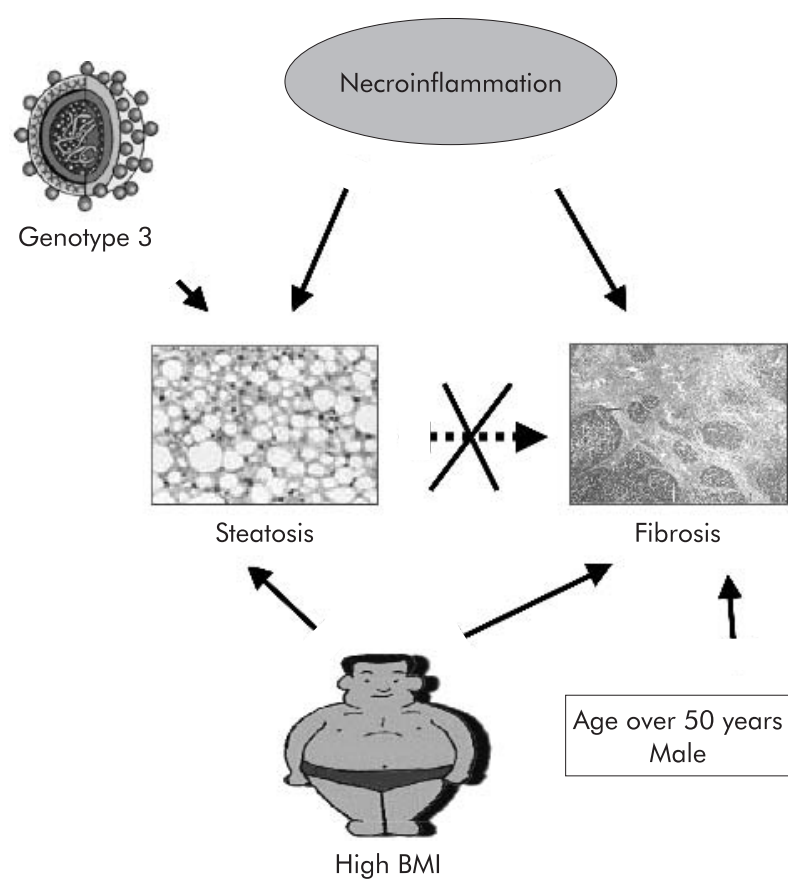

Figure 1 Steatosis in chronic hepatitis $C$. In our population with chronic hepatitis $\mathrm{C}$, we found on the one hand that steatosis was associated with a high body mass index (BMI), high grade of necroinflammation, and genotype 3 , and on the other hand that fibrosis was associated with male sex, high BMI, and high grade of necroinflammation. There was no association between steatosis and fibrosis.

in overweight patients that are free of any other cause of liver disease. ${ }^{11}$ However, in this study, no relationship was found between the degree of steatosis and BMI. Interestingly, in another setting (alcoholic patients), increased body weight was found to be associated with liver lesions. ${ }^{12}$ Circulating leptin is increased in obesity. Leptin increases transforming growth factor $\beta 1$ which is an important profibrogenic cytokine in liver fibrosis. ${ }^{13}$ Therefore, in chronic hepatitis $\mathrm{C}$, BMI could lead to fibrosis through mechanisms other than steatosis.

We found no significant association between the presence of steatosis or fibrosis and alcohol consumption. This result is in accordance with previous studies. ${ }^{4-6}$ However, controversial results were reported..$^{14}$ A possible explanation for these discrepancies is that some studies, in common with ours, excluded patients with a heavy alcohol intake. Another explanation could be that steatosis in most cases, at least in our population, is an innocent finding associated with hepatitis $\mathrm{C}$ infection, and may be associated with fibrosis in a subgroup of patients. For example, pure alcoholic fatty liver was found to be associated with a risk of progression to cirrhosis in univariate analyses but when multivariate analysis was used, the grade of steatosis was not associated with a high risk of progression to hepatic fibrosis and/or cirrhosis. ${ }^{15}$

In our cohort study, using multivariate analysis (taking into account confounding factors associated with steatosis), we found a relationship between hepatic steatosis and HCV genotype 3 . When statistic analysis was performed in patients with important steatosis $(>60 \%)$, genotype 3 was the main associated factor. An association between steatosis and HCV genotype 3 was previously reported but several studies included small patient populations and confounding variables for steatosis were not always excluded. ${ }^{46}{ }^{17}$ In our study, in a large population and excluding confounding factors, we can confirm that genotype 3 is associated with steatosis. Furthermore, we showed in a previous study that genotype 3 was associated with higher quasispecies heterogeneity. ${ }^{18}$

In vitro studies and the transgenic mouse model have both suggested that the HCV core protein is possibly responsible for lipid accumulation. ${ }^{19} 20$ It has recently been reported in transgenic mice that HCV core protein could inhibit microsomal triglyceride transfer protein activity and very low density lipoprotein secretion, leading to steatosis. ${ }^{21}$ In another study, core protein expression in transgenic mice was confirmed to lead to steatosis but the mechanism postulated seemed to be related to mitochondrial toxicity with production of reactive oxygen species. ${ }^{22}$ All in vitro models have used constructs derived from genotype 1 isolates. Further studies using genotype 3 isolates are needed.

Interestingly, in our study, using multivariate analysis, we found an association between steatosis and high grade of necroinflammation $(p<0.0001)$. Necroinflammation is a dynamic process and may fluctuate over time, and could accelerate fibrosis progression. There are several mechanisms which may explain the relationship between steatosis and necroinflammation. An in vitro study has shown that the HCV core protein could lead to oxidative stress. ${ }^{23}$ In addition, steatosis of any cause can be associated with the development of inflammatory changes in the setting of oxidative stress. ${ }^{24}$ Moreover, HCV is associated with increased production of cytokines ${ }^{25}$ that enhance inflammation.

Furthermore, in our study, using multivariate analysis, we found an association between high grade of necroinflammation and fibrosis $(p<0.0001)$. The association between fibrosis progression and necroinflammatory activity scores on liver biopsy is controversial. In a study on a single liver biopsy, there was little or no correlation between severity of necroinflammatory activity and degree of fibrosis. ${ }^{3}$ However, necroinflammatory activity is a dynamic process in chronic hepatitis $\mathrm{C}$ and may fluctuate over time. The activity score likely reflects the severity of necrosis and inflammation at a given point. In some cross sectional studies and in most longitudinal studies, the degree of necroinflammatory activity was associated with subsequent progression of fibrosis. $^{6}{ }^{2627}$ There is reason to believe that the necroinflammatory process is implicated in the fibrogenesis process because stellate cells are activated around necroinflammatory lesions. $^{28}$

In conclusion, in our population of patients with chronic hepatitis C, fibrosis was not associated with steatosis but with necroinflammation (fig 1). This result suggests that steatosis is not a significant determinant of fibrosis in patients with chronic hepatitis $\mathrm{C}$ without metabolic disorders which are known risk factors for non-alcoholic steatohepatitis. As we found an association between high BMI and fibrosis, we recommend counselling for body weigh control in patients with chronic hepatitis C.

\section{ACKNOWLEDGEMENTS}

The study was supported by a grant from Agence Nationale pour la Recherche contre le SIDA (ANRS). We thank Dominique Pessayre for helpful discussion.

\section{Authors' affiliations}

T Asselah, N Boyer, K Nahon, M Martinot, D Valla, P Marcellin,

Fédération d'Hépato-Gastroentérologie and INSERM U 481 and Centre de Recherche Claude Bernard sur les Hépatites Virales, AP-HP Hôpital Beaujon, Clichy, France

M-C Guimont, H Daikha, D Vidaud, M Vidaud, Service de Biochimie, AP-HP Hôpital Beaujon, Clichy, France

D Cazals-Hatem, C Degott, Service d'Anatomie Pathologique, AP-HP Hôpital Beaujon, Clichy, France

F Tubach, Département d'Epidémiologie, Biostatistique et Recherche Clinique, AP-HP Hôpital Bichat, Paris, France 


\section{REFERENCES}

1 Wasley A, Alter MJ. Epidemiology of hepatitis C: geographic differences and temporal trends. Semin Liver Dis 2000;20:1-16.

2 Marcellin P, Asselah T, Boyer N. Fibrosis and disease progression in hepatitis C. Hepatology 2002;36:S47-56.

3 Poynard T, Bedossa P, Opolon P. Natural history of liver fibrosis progression in patients with chronic hepatitis C. The OBSVIRC, METAVIR, CLINIVIR, and DOSVIRC groups. Lancet 1997;349:825-32.

4 Adinolfi LE, Gambardella M, Andreana A, et al. Steatosis accelerates the progression of liver damage of chronic hepatitis $C$ patients and correlates with specific HCV genotype and visceral obesity. Hepatology 2001:33:1358-64.

5 Hourigan LF, Macdonald GA, Purdie D, et al. Fibrosis in chronic hepatitis C correlates significantly with body mass index and steatosis. Hepatology 1999:29:1215-19.

6 Monto A, Alonzo J, Watson JJ, et al. Steatosis in chronic hepatitis C: relative contributions of obesity, diabetes mellitus, and alcohol. Hepatology 2002;36:729-36.

7 Mihm S, Fayyazi A, Hartmann H, et al. Analysis of histopathological manifestations of chronic hepatitis $C$ virus infection with respect to virus genotype. Hepatology 1997;25:735-9.

8 Czaja AJ, Carpenter HA, Santrach PJ, et al. Host- and disease-specific factors affecting steatosis in chronic hepatitis C. J Hepatol 1998;29:198-206.

9 Stuyver L, Rossau R, Wyseur A, et al. Typing of hepatitis $C$ virus isolates and characterization of new subtypes using a line probe assay. J Gen Virol 1993;74:1093-102.

10 Bedossa P, Poynard T. An algorithm for the grading of activity in chronic hepatitis C. The METAVIR Cooperative Study Group. Hepatology 1996;24:289-93.

11 Ratziu V, Giral P, Charlotte F, et al. Liver fibrosis in overweight patients. Gastroenterology 2000;118:1117-23.

12 Iturriaga $H$, Bunout $D$, Hirsch $S$, et al. Overweight as a risk factor or a predictive sign of histological liver damage in alcoholics. Am J Clin Nutr 1988:47:235-8.

13 Anania FA. Leptin, liver, and obese mice-fibrosis in the fat lane. Hepatology 2002;36:246-8.

14 Serfaty L, Poujol-Robert A, Carbonell N, et al. Effect of the interaction between steatosis and alcohol intake on liver fibrosis progression in chronic hepatitis $C$. Am J Gastroenterol 2002:97:1807-12.
15 Teli MR, Day CP, Burt AD, et al. Determinants of progression to cirrhosis or fibrosis in pure alcoholic fatty liver. Lancet 1995;346:987-90.

16 Rubbia-Brandt L, Leandro G, Spahr L, et al. Liver steatosis in chronic hepatitis C: a morphological sign suggesting infection with HCV genotype 3 . Histopathology 2001;39:1 19-24.

17 Rubbia-Brandt L, Quadri R, Abid K, et al. Hepatocyte steatosis is a cytopathic effect of hepatitis $C$ virus genotype 3 . J Hepatol 2000;33:106-15.

18 Asselah T, Martinot M, Cazals-Hatem D, et al. Hypervariable region 1 quasispecies in hepatitis $C$ virus genotypes $1 \mathrm{~b}$ and 3 infected patients with normal and abnormal alanine aminotransferase levels. J Viral Hepat 2002;9:29-35

19 Barba G, Harper F, Harada T, et al. Hepatitis C virus core protein shows a cyłoplasmic localization and associates to cellular lipid storage droplets. Proc Natl Acad Sci U S A 1997;94:1200-5.

20 Moriya K, Fujie $\mathrm{H}$, Shintani $\mathrm{Y}$, et al. The core protein of hepatitis $\mathrm{C}$ virus induces hepatocellular carcinoma in transgenic mice. Nat Med 1998:4:1065-7.

21 Perlemuter G, Sabile A, Letteron P, et al. Hepatitis $C$ virus core protein inhibits microsomal triglyceride transfer protein activity and very low density lipoprotein secretion: a model of viral-related steatosis. FASEB $J$ 2002; 16:185-94.

22 Lerat $\mathrm{H}$, Honda $\mathrm{M}$, Beard MR, et al. Steatosis and liver cancer in transgenic mice expressing the structural and nonstructural proteins of hepatitis $C$ virus. Gastroenterology 2002;122:352-65.

23 Okuda M, Li K, Beard MR, et al. Mitochondrial injury, oxidative stress, and antioxidant gene expression are induced by hepatitis $\mathrm{C}$ virus core protein. Gastroenterology 2002;122:366-75.

24 Day CP, James OF. Steatohepatitis: a tale of two "hits"? Gastroenterology $1998 ; 114: 842-5$.

25 Neuman MG, Benhamou JP, Malkiewicz IM, et al. Kinetics of serum cytokines reflect changes in the severity of chronic hepatitis $C$ presenting minimal fibrosis. J Viral Hepat 2002;9:134-40.

26 Yano $M$, Kumada $H$, Kage $M$, et al. The long-term pathological evolution of chronic hepatitis C. Hepatology 1996;23:1334-40.

27 Ghany MG, Kleiner DE, Alter HJ, et al. Progression of fibrosis in chronic hepatitis C. Gastroenterology 2003;124:97-104.

28 Baroni GS, Pastorelli A, Manzin A, et al. Hepatic stellate cell activation and liver fibrosis are associated with necroinflammatory injury and Th1-like response in chronic hepatitis C. Liver 1999;19:212-19. 